\title{
Armin Kreiner, \\ Jesus, UFOs, Aliens Außerirdische Intelligenz als Herausforderung für den christlichen Glauben, Freiburg/ \\ Basel/Wien: Herder 2010,

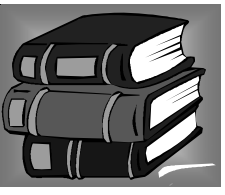

$218 \mathrm{hlm}$.

Belum begitu lama dua buah berita menggoncangkan dunia (astrofisika). Yang pertama, CERN, Pusat penelitian atom di Geneva, yang dalam dua eksperimen berturut-turut menemukan bahwa neutrino (bagian mikro paling kecil) bergerak dengan kecepatan sedikit melampaui kecepatan cahaya. Yang kedua, pada minggu kedua Januari yang lalu pengamatan astronomis mutakhir menengarai bahwa dalam Bimasakti kita rata-rata setiap dari 10 milyar bintangnya mempunyai sekurang-kurangnya satu planet yang mirip dengan planet kita, bumi.

Berita pertama begitu dahsyat sehingga para ahli fisika yang membuat eksperimen itu belum mau mempercayainya, karena kalau amatan mereka betul, salah satu pilar fisika modern - teori relativitas khusus Einsteinruntuh. Sebuah revolusi baru dalam fisika. Salah satu implikasinya: kemungkinan menjalin komunikasi dengan extraterrestrial intelligence (ETI) - kalau ada-bertambah besar.

Berita kedua lebih dahsyat lagi implikasinya. Sampai sekarang banyak astronom berpendapat bahwa probabilitas terjadinya planet dengan ciri-ciri seperti bumi adalah sedemikian kecil sehingga tidak mustahil kalau manusia merupakan satu-satunya makhluk berakal-budi di alam raya. Tetapi kalau di Bimasakti kita saja - satu di antara (diperkirakan) $10^{11}$ Bimasakti di seluruh alam raya - terdapat 10 milyar planet mirip bumi, adanya makhluk berakal budi di luar bumi (aliens) merupakan kemungkinan kuat.

Dua penemuan ini mengangkat salah satu tantangan paling serius bagi teologi Kristiani: kalau ada makhluk berakal budi di tempat lain di 
alam raya, apa implikasinya bagi inti iman Kristiani, peristiwa Yesus Kristus? Apakah mereka juga perlu ditebus dari dosa? Dan kalau perlu, apakah karya penebusan Yesus juga berlaku bagi mereka? Kalau penyelamatan ilahi di planet-planet tidak berkaitan dengan Yesus Kristus, apa Yesus Kristus masih mempunyai relevansi universal dalam rencana penyelamatan ilahi?

Pertanyaan-pertanyaan ini bukanlah pertanyaan iseng-iseng, melainkan menyangkut hakikat iman Kristiani. Persis masalah inilah yang dibahas oleh Armin Kreiner - guru besar teologi fundamental pada Fakultas Teologi Katolik Universitas München-dalam bukunya (yang, sayang, baru tersedia dalam bahasa Jerman). Buku ini membahas tantangan bagi teologi Kristiani andaikata ternyata selain manusia ada makhluk berakal budi lain di alam raya.

Kreiner membagi bukunya dalam dua bagian. Dalam 135 halaman pertama yang sangat informatif ia meninjau laporan-laporan tentang hubungan yang diklaim sudah terjadi antara manusia dengan aliens. Seluruh debat tentang UFO (unknown flying objects), serta juga usaha search for extra-terrestrial intelligence (SETI) dipaparkan dengan rinci. Namun kesimpulannya sederhana: sama sekali tidak ada bukti bahwa pernah terjadi kontak dengan aliens. Semua laporan dari ribuan saksi entah tidak dapat dipercayai, entah dapat juga dijelaskan secara lebih sederhana, atau sekurang-kurangnya tidak beralasan untuk dihubungkan dengan aliens. Sementara itu, SETI sampai sekarang belum menemukan sinyal apa pun.

Akan tetapi hal itu tidak berarti bahwa masalahnya hilang, karena kalau pun adanya aliens tidak dapat dipastikan, kemungkinannya tidak dapat disangkal. Teologi Katolik - sesudah menyatakan tidak berkeberatan dengan ajaran evolusi ${ }^{1}$ - tidak memiliki keberatan dengan pengandaian bahwa apabila kondisi-kondisinya cocok, perkembangan

1 Tentang evolusi dalam perspektif teologi monoteis dapat dilihat artikel penulis, "Allah dan Alam: Darwinisme, Creationism, Intelligent Design, Sebuah Tinjauan Kritis," Diskursus 8 (April 2009): 1-27. 
organisme seperti di bumi kita dapat terjadi di planet lain. Kalau dalam setiap dari $10^{11}$ Bimasakti yang sekarang diperkirakan ada di alam raya terdapat satu planet seperti bumi saja, maka di alam raya bisa ada $10^{11}$ planet dengan organisme-organisme hidup, apalagi kalau benar bahwa dalam Bimasakti kita saja sudah ada milyaran planet seperti bumi.

Dalam bagian kedua bukunya Kreiner membahas implikasi kemungkinan adanya makhluk berakal budi lain di alam raya - entah kita pernah akan bisa berkomunikasi dengan mereka entah tidak-bagi teologi Kristiani. Dengan cukup panjang lebar (dan sedikit melingkar-lingkar) Kreiner membahas alternatif-alternatif yang ada.

Penolakan terhadap adanya ETI di planet lain dengan alasan bahwa eksistensi ETI tidak dapat disesuaikan dengan kristologi-sebagaimana diperjuangkan oleh teolog Anglikan Brian Hebblethwaite-ditolak sebagai posisi yang sama konyolnya dengan creationism. Apakah mungkin bahwa aliens tidak jatuh ke dalam dosa sehingga tidak perlu ada penebusan? Kemungkinan itu pun perlu ditolak. Begitu aliens merupakan makhluk berakal budi, mereka memiliki kebebasan dan dapat - dan kiranya akan berdosa. Apakah mungkin mereka dibiarkan dalam dosa? Tentu tidak. Tidak mungkin Allah menawarkan keselamatan hanya kepada manusia di bumi. Apakah penebusan sebagai buah pengurbanan diri Yesus di salib juga memancar ke planet-planet lain? Kreiner menolak kemung-kinan ini secara meyakinkan. Menurutnya, pikiran itu tercemar oleh "skandal partikularitas," yaitu anggapan bahwa kita, manusia penghuni planet bumi, mempunyai kedudukan istimewa di antara semua makhluk berakal budi lain di alam raya. Suatu penebusan (penebusan oleh Yesus di dunia) yang tidak diketahui sama sekali oleh mereka yang ditebus - yang karena itu juga tidak bisa mereka akui dan tidak bisa mereka syukuri-tidaklah masuk akal.

Kreiner menyarankan agar teologi Kristiani menerima saja pengandaian bahwa Allah menunjukkan rahmat dan belas kasih-Nya di seluruh alam raya dengan kualitas cinta (bukan dengan cara) yang sama. Kalau inkarnasi adalah cara Allah menunjukkan solidaritas-Nya dengan 
manusia, inkarnasi tidak mungkin terbatas hanya kepada bumi. Tetapi hal itu langsung menimbulkan pertanyaan, apakah Pribadi Kedua Tritunggal - mari kita sebut dalam bahasa Kristiani "Sang Putera" harus berinkarnasi di semua planet itu (Kreiner bertanya terus: lantas disiksa, dibunuh dan bangkit dari mati)? Menurut Kreiner, waktu yang tersedia tidak cukup (misalnya diperhitungkan rata-rata 30 tahun per inkarnasi) untuk melakukan inkarnasi di semua planet. Anggapan bahwa Sang Putera seakan-akan mengembara dari planet ke planet untuk selalu melakukan karya penebusan yang sama dinilainya absurd.

Ada hal menarik yang ditunjuk Kreiner. Eksoteologi-teologi yang memikirkan masalah-masalah teologis berkaitan dengan kemungkinan ETI - ini berhadapan dengan masalah mirip dengan teologi agama-agama. Lima ratus tahun lalu Kristianitas pernah mengalami shock; yakni ketika disadari bahwa Kristianitas hanyalah minoritas di antara agama-agama di bumi dan bahwa sebagian cukup besar dari mereka sedikit pun tidak menunjuk-kan tanda-tanda bahwa mereka mau masuk Kristianitas. Tantangan itu akhirnya dijawab oleh Gereja Katolik dalam Konsili Vatikan II (Lumen Gentium, 16 dan Nostra Aetate). Namun posisi “inklusivis" Konsili itu - kepada semua orang ditawarkan keselamatan, tetapi kepenuhan ke-benaran diwahyukan Allah dalam Yesus Kristus - sekarang oleh beberapa teolog "pluralis" dianggap terkena "skandal partikularitas," juga karena mempertahankan keunggulan prinsipiil wahyu dalam Yesus Kristus. Kreiner bertanya, apakah eksoteologi harus mengikuti teolog "pluralis" seperti John Hick ${ }^{2}$ dan Perry Schmidt-Leukel yang menuntut agar "semua klaim atas normativitas dan superioritas dilepaskan dan diandaikan bahwa Allah masuk ke dalam sejarah agama-agama dunia dalam pelbagai manifestasi yang berbeda, tetapi secara prinsip sama nilainya" (hlm. 186)? Maksud Kreiner adalah apakah kita harus mengatakan bahwa inkarnasi Allah dalam manusia Yesus hanyalah salah satu inkarnasi dan Allah menginkarnasikan diri juga di semua planet berpenghuni makhluk berakal budi, dengan cara yang sesuai dengan

2 Tentang John Hick, lih. bahasan penulis dalam Diskursus 9 (April 2010): 114-117. 
kondisi-kondisi di planet itu? Tetapi kalau begitu, bagaimana hal keistimewaan, keunikan, dan nilai universal peristiwa Yesus Kristus yang diyakini Kristianitas?

Menurut Kreiner, teologi harus berani bertanya, "A pakah yang terjadi dalam Yesus Kristus tidak juga dalam salah satu bentuk terjadi di tempat dan di waktu-waktu lain. Itu disertai percobaan-percobaan teologis untuk mengartikan paham seperti 'inkarnasi' dan 'Allah menjadi manusia' dalam suatu cara yang bisa diterapkan juga di luar tradisi biblis-Kristiani. Dengan sendirinya ini berarti bahwa dua pilar keyakinan tak tertawarkan kristologi tradisional, keunikan historis serta makna keselamatan universal peristiwa Kristus, dipikirkan kembali" (hlm. 175). Teologi harus kembali ke pertanyaan dasar: "apa artinya 'Allah menjadi manusia'” (hlm. 171)?

Kreiner berpendapat bahwa kristologi tertradisi (tradisional) tidak mampu menjawab pertanyaan-pertanyaan itu. Kristologi klasik merupakan "teologi dari atas" di mana "peristiwa Yesus Kristus" dipahami sebagai "Pribadi Ilahi Kedua, jadi sebagai 'subjek', yang seakan-akan mengunjungi semua planet berpenghuni" (hlm. 173). Kreiner menganggap gagasan "loncat planet" itu sebagai hal yang aneh. Yang diperlukan adalah sebuah "teologi dari bawah" yang memahami inkarnasi dalam kaitannya dengan penciptaan. Namun penciptaan lantas tidak boleh dipahami sebagai “hubungan kausal di mana Allah, Sang Pencipta, menyebabkan eksistensi realitas yang berbeda dari Diri-Nya sendiri, yaitu ciptaan, di mana hubungan itu merupakan hubungan lahiriah" (hlm. 183) melainkan penciptaan dapat juga dipahami sebagai tindakan manifestasi diri Allah; yakni bahwa Allah menyatakan diri dalam ciptaan-Nya. Jadi penciptaan sendiri sudah merupakan inkarnasi. Apabila Allah bukannya memanggil ke dalam eksistensi sebuah realitas yang secara radikal berbeda dari padaNya, melainkan mengungkapkan diri sendiri dalam ciptaan-Nya, seperti seniman dalam karyanya, terbukalah jalan untuk memahami penciptaan dan inkarnasi tidak sebagai dua realitas terpisah, melainkan sebagai dua sudut dari sebuah realitas yang satu dan sama. Allah lantas menginkarnasikan diri tidak hanya dalam Yesus Kristus, melainkan dalam 
seluruh ciptaan-Nya. Penjelmaan Allah (dalam Yesus Kristus: peninjau buku) menjadi bagian dan lanjutaan dari Allah menjadi dunia" (hlm. 183). "Inkarnasi lantas tidak lagi dimengerti sebagai masalah jadi tidak jadi, sebagaimana disindirkan oleh ajaran tradisional tentang dua kodrat (Yesus: peninjau buku), melainkan dimengerti sebagai sebuah proses gradual dengan kepadatan yang berbeda" (hlm. 184). Maka seluruh ciptaan merupakan "inkarnasi." Tidak lagi ditanyakan apakah dalam ciptaan tertentu, misalnya di planet bumi, ada inkarnasi, melainkan yang dibedakan adalah "kepadatan" inkarnasi. Dalam Yesus inkarnasi Ilahi mencapai suatu kepadatan sangat intensif.

Tetapi apakah kita lantas masih dapat mengatakan bahwa Allah memanifestasikan diri "dalam Yesus Kristus secara unik, tanpa tanding dan tidak terlampaui?" (hlm. 185). Kreiner tidak menjawab pertanyaannya ini secara tegas. Ia hanya menegaskan bahwa wacana "Allah menjadi manusia" memerlukan pengartian yang lebih mendalam. Menurut Kreiner, "kaum Kristiani bisa menemukan dalam peradabanperadaban luar bumi kehadiran Allah yang sama yang menurut mereka menginkarnasikan diri dalam Yesus Kristus." Dan ia menambahkan: "Jauh di masa mendatang barangkali perselisihan apakah Allah mewahyukan diri lebih dalam agama tertentu atau peradaban tertentu dari pada di tempat lain menjadi masa lampau" (hlm. 187). Ia mengakhiri bukunya dengan satu bab yang membahas tentang apakah aliens juga bisa beragama? (Ia membenarkan pertanyaan ini).

Apakah Kreiner berhasil menjawab pertanyaan-pertanyaan teologis berat yang diajukannya sendiri? Inti masalahnya adalah bagaimana dua keyakinan berikut dapat dipersatukan. Pertama, bahwa kalau ada ETI di alam raya, mereka tidak kurang dicintai oleh Allah dari pada manusia bumi dan karena itu inkarnasi ilahi tidak mungkin merupakan kejadian hanya di planet bumi. Kedua, bahwa dalam manusia Yesus Allah mewahyukan diri sendiri secara unik dengan makna penyelamatan universal. Dan hal itu perlu dijawab tanpa jatuh ke dalam pluralisme relativistik àla Knitter, Hick dan Schmidt-Leukel di mana Yesus hanyalah 
salah satu dari pewahyuan diri Allah yang pada hakikatnya semua sama derajatnya. Kiranya Kreiner berhasil merumuskan tantangan. Ia menunjukkan arah pemecahannya, tetapi ia belum memecahkannya. Bisa diteliti apakah pemecahan dapat dicari ke arah pemikiran baru tentang Pan-en-teisme sebagai pola yang lebih cocok untuk memahami hubungan antara Sang Pencipta dan ciptaan, sebagaimana akhir-akhir ini diangkat oleh beberapa teolog (Herderkorrespondenz Spezial 2-2011). Yang jelas, kemungkinan adanya aliens menghadapkan teologi Kristiani dengan tantangannya yang barangkali paling berat, yang sampai sekarang pernah dihadapinya.

Sebagai catatan penutup, tetap benar bahwa probabilitas adanya ETI, melawan segala tulisan populer dan ilmiah (sampai sekarang), tetap minim! Probabilitas matematis bahwa di sebuah planet dengan kondisikondisi seperti bumi kita terjadi evolusi sampai ke kehidupan intelektual adalah kurang dari satu di antara $10^{100}$ (bdk. Erbrich, 1988, dll.). Kalaupun dalam setiap dari seluruh $10^{11}$ Bimasakti terdapat 10.000 planet mirip bumi, maka jumlah planet di alam raya yang kondisikondisinya mirip bumi adalah $10^{15}$. Jadi probabilitas adanya ETI tetap teramat rendah. Kemungkinan besar kita tidak pernah akan mengetahui apakah ada ETI. Selama itu pertimbangan-pertimbangan dramatis di atas bisa saja hanyalah sebuah permainan teologis, namun dengan daya tantang yang memang tinggi. (Franz Magnis-Suseno, Program Pascasarjana, Sekolah Tinggi Filsafat Driyarkara, Jakarta).

\footnotetext{
Daniel Boyarin,

The Jewish Gospels: The Story of the Jewish Christ, Forwarded by Jack Miles, New York: The New Press, 2012, xxiii +200 hlm.

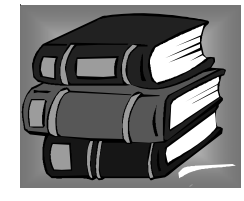

Sudah sejak awal abad pertama Kristianisme memisahkan diri dari tradisi Yudaisme dan menjadi agama baru sama sekali, meskipun Yesus yang menjadi pokok iman mereka adalah seorang Yahudi. Agama Kristen diajarkan oleh Yesus dengan melepaskan diri dari tradisi Yahudi yang ortodoks, demikianlah anggapan umum hingga sekarang. Maka
} 